Revista de la red interuniversitaria de estudios sobre las literaturas rioplatenses contemporáneas en Francia

$6 \mid 2011$

Juan José Saer. archivos, memoria, critica

\title{
Un narrador sobre el caballo de la calesita
}

Estudio genético de los incipits y los excipits en la narrativa de Juan José Saer

\section{Graciela Villanueva}

\section{OpenEdition}

\section{Journals}

Edición electrónica

URL: http://journals.openedition.org/lirico/211

DOI: $10.4000 /$ lirico. 211

ISSN: 2262-8339

Editor

Réseau interuniversitaire d'étude des littératures contemporaines du Río de la Plata

\section{Edición impresa}

Fecha de publicación: 1 diciembre 2011

Paginación: 93-113

ISBN: 2-9525448-5-9

ISSN: 2263-2158

\section{Referencia electrónica}

Graciela Villanueva, " Un narrador sobre el caballo de la calesita », Cuadernos LIRICO [En línea], 6 | 2011, Puesto en línea el 01 julio 2012, consultado el 04 mayo 2019. URL : http:// journals.openedition.org/lirico/211; DOI : 10.4000/lirico.211

\section{cc) (†) $\ominus$}

Cuadernos LIRICO está distribuido bajo una Licencia Creative Commons Atribución-NoComercialSinDerivar 4.0 Internacional. 


\section{UN NARRADOR SOBRE EL \\ CABALLO DE LA CALESITA. \\ ESTUDIO GENÉTICO DE LOS INCIPITS Y LOS EXCIPITS EN LA NARRATIVA DE JUAN JOSÉ SAER.}

Graciela VillanUEVA IMAGER-CREER, Université Paris Est-Créteil

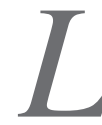

a grande (2005) de Juan José Saer tiene como eje el relato de lo que ocurre durante una semana que ni empieza un lunes ni termina un domingo, sino que empieza un martes y termina el lunes siguiente. La grande arranca en una semana empezada y se cierra en otra que acaba de empezar. Lo que podría parecer un detalle o una desprolijidad tiene un sentido muy preciso para los lectores de la obra de Saer, que saben que treinta años antes en "Recuerdos" (en La mayor, 1976) el escritor ya manifestaba su aspiración a una narración sin "principio ni fin", una narración circular en la que "la posición del narrador sería semejante a la del niño sobre el caballo de la calesita" que "trata de agarrar a cada vuelta los aros de acero de la sortija" y que vuelve "la mayor parte de las veces con las manos vacías". La insistencia en la continuidad y la presentación de cada nuevo texto como parte de un perpetuo fluir son elementos sobre los que la crítica saeriana ha vuelto muy a menudo. La plasmación metafórica más evidente de esta idea es la imagen del río (el de Heráclito, el del Paraíso de Dante citado en un epígrafe de La grande, pero sobre todo y ante todo, el Paraná). El escamoteo por parte de Saer de lo autobiográfico-anecdótico no es más que uno de los correlatos de su esfuerzo por borrar o, para decirlo más precisamente, por borronear, las marcas del comienzo ${ }^{1}$.

\footnotetext{
${ }^{1}$ Cf. Julio Premat, "El escritor no es nadie" en La dicha de Saturno, Rosario, Beatriz Viterbo, 2002, p. 267 y siguientes y "Saer: un escritor del lugar", en su Héroes sin atributos, Buenos Aires, Fondo de Cultura Económica, 2009, pp. 167-202.
} 
Ahora bien, en tensión con este énfasis en la continuidad, también es evidente (para el público y para la crítica) la importancia de la temática del origen: en el corpus saeriano se repiten escenas de escritura, figuraciones de autor, mitos de origen y sobre todo un lugar al que muchas veces y de muchas maneras se vuelve. No es casual que el núcleo recurrente, obsesivo, imaginario, en la obra de Saer no sea un hecho ni una serie de hechos sino una zona. De un lugar se da cuenta a través de la descripción, modalidad del discurso en la que la linealidad y la referencia a un principio y a un final tienen un peso relativamente menor, sobre todo en comparación con el discurso narrativo, que en la tradición literaria y en la comunicación cotidiana está sometido a los dictados de la cronología y la causalidad.

En la ficción saeriana la cuestión del origen puede considerarse en muchos niveles:

a) su significación más general -genésica y genética- remite a la temática del origen tout court y, en una variante de alcance metatextual, a la cuestión del origen de la escritura,

b) en un sentido más acotado, que podríamos llamar genético-textual, el origen es el de los textos, aspecto que puede estudiarse a partir de la consulta de los manuscritos del autor,

c) y, por último, en un sentido textual, más acotado todavía, de lo que se trata es de analizar los incipits y excipits de los cuentos y novelas del corpus.

Partiendo de la convicción de que las zonas de apertura y cierre de un texto, en particular en el caso de un texto de ficción, son lugares privilegiados del flujo intertextual y de la comunicación entre el texto y el mundo, el objetivo de estas páginas es volver, incorporando los aportes de la crítica genética, sobre las figuras de la continuidad y sobre los modos en que aparece la temática del origen en los bordes de las ficciones saerianas. El punto de partida será el análisis genético de algunos incipits ${ }^{2}$. La escritura de las primeras líneas, e incluso en algunos casos de las primeras páginas -sobre todo cuando se trata de novelas- es, en efecto, un proceso que deja marcas relativamente

\footnotetext{
${ }^{2}$ La consulta de los manuscritos del escritor fue realizada durante el proceso de ordenamiento del fondo Saer, entre 2008 y 2010, que llevó a cabo un equipo integrado por Sergio Delgado, Mariana Di Ció, Pénélope Laurent, Valentina Litvan, Julio Premat, Diego Vecchio y Graciela Villanueva.
} 
fáciles de localizar en los manuscritos. Los borradores de los excipits, en cambio, suelen hallarse dispersos en marginalias, papelitos, etc. o pueden a veces incluso quedar fuera de todo alcance: Saer, según sus propias declaraciones, solía reescribir largamente en su cabeza las últimas frases de una novela, sin necesidad de pasar por la escritura ${ }^{3}$.

Mucho se ha hablado de la repetición de los personajes y los vasos comunicantes entre las diferentes novelas y cuentos de Juan José Saer, o de la reaparición de reflexiones y motivos comunes, o de los finales abiertos o "suspendidos" ${ }^{\text {" }}$ Mi objetivo es volver ahora sobre otras tres figuras de la continuidad recurrentes en el corpus saeriano y enriquecer su estudio con el análisis de algunos manuscritos.

\section{I) In media verba}

En los cuentos y novelas de Saer son frecuentes los incipits en los que los coordinantes, deícticos, pronombres personales, demostrativos e indefinidos remiten a una secuencia ya empezada. He aquí algunos de los ejemplos más elocuentes:

“AMANECE / Y YA ESTÁ CON LOS OJOS ABIERTOS." (El limonero real, 1974)

"Otros, ellos, antes, podían. Mojaban, despacio, en la cocina, en el atardecer, en invierno, la galletita..." (“La mayor" en La mayor, 1976)

\footnotetext{
${ }^{3}$ Esto no significa en absoluto que Saer creyera que el excipit es poco relevante. Muy por el contrario, Saer siempre reconoció la importancia del final -e incluso de la frase final- de un texto de ficción, incluso desde el punto de vista genético. El hallazgo de un final es, en efecto, el elemento que en muchos casos pone en movimiento la escritura de Saer. En una entrevista de 2005, realizada al concluir el trabajo genético sobre Glosa y El entenado, Saer declaraba: “... en casi todas mis novelas, en todas, el final está pensado prácticamente desde el principio y todo va hacia ese final. Es posible entonces que lo haya escrito antes. Hay muchas frases que están escritas en borradores, que están en otros lados, que escribo e incorporo después al texto. [...] [Lo importante es] tener la escena final. Saber dónde empieza y dónde termina, no sólo por el tiempo, la duración, sino saber adónde va. Cuando uno sabe adónde va... Por ejemplo el final de esta novela [que estoy escribiendo, es decir La grande] ya lo tengo pensado desde hace mucho tiempo [...], la última frase ya está." ( $C f$. Julio Premat, Diego Vecchio y Graciela Villanueva, Entrevista a Juan José Saer del 4 de marzo de 2005, en Juan José Saer, Glosa. El entenado, Córdoba (Argentina), Alción Editora /colección Archivos de l’UNESCO, 2010, pp. 923-932).

${ }^{4}$ El carácter abierto es más evidente en los casos de ficciones que presentan enigmas que no se resuelven: por ejemplo quién es el asesino de los caballos en Nadie, nada, nunca, quién es el padre de la criatura en La ocasión, quién escribió el dactilograma o quién mató realmente a las viejecitas en La pesquisa y, sobre todo, quién fue el que vino a llevarse para siempre al Gato y a Elisa.
} 
"Pero en el río las orillas destellan, lentas, como señales: cabrillean." ("Balnearios" en La mayor, 1976)

"De esas costas vacías me quedó sobre todo la abundancia de cielo." (El entenado, 1983)

“Llamémoslo nomás Bianco" (La ocasión, 1988)

"Pasaron, como venía diciendo hace un momento, veinte años: anochece" (Lo imborrable, 1992)

"Allá, en cambio, en diciembre, la noche llega rápido" (La pesquisa, 1994)

(El subrayado es nuestro)

Esta modalidad de insistencia en la continuidad en el comienzo mismo es un rasgo muy evidente en la ficción saeriana: Alan Pauls lo subrayó en "Empezar por pero" (un artículo publicado en Clarín en el momento de la muerte de Saer) y la misma idea apareció en el texto titulado "Como venía diciendo", que Martín Kohan leyó en el homenaje a Saer realizado el 9 de septiembre de 2005 en el Auditorio del MALBA en Buenos Aires. Con estos incipits como telón de fondo, el comienzo y el final del dactilograma encontrado entre los papeles de Washington Noriega y presentado en el capítulo 2 de La pesquisa cobran todo su sentido:

Lo que le ha llamado antes que nada la atención es que la novela empieza con puntos suspensivos, y que en realidad la primera no es una frase entera sino el miembro conclusivo de una frase de la que falta toda la parte argumentativa:

... prueba de que es sólo el fantasma lo que engendra la violencia.

Desplazando el paquete entero de hojas, menos la última que lleva, en el ángulo superior derecho, el número 815, Pichón ha podido comprobar que la frase final también se interrumpe y acaba, no con un punto, sino con tres puntos suspensivos.

En su trabajo sobre el incipit novelesco, Andrea del Lungo estudia una serie de "ataques", muy frecuentes en el Nouveau roman, y que tienen características semejantes a estos comienzos de Saer ${ }^{5}$. Más que incipits in medias res -dice Del Lungo- se trata de incipits in media verba e incluso in media scripta, ya que son comienzos que no ponen el

${ }^{5}$ Del Lungo llama "ataque" a la primera frase del incipit. Cf. Andrea Del Lungo, L'incipit romanesque, Paris, Seuil, 2003, p. 54. 
acento en la referencia a una realidad preexistente sino en la continuidad respecto de un relato -y aun respecto de un texto- ya comenzados (Del Lungo cita el caso extremo de Claude Simon que, como el autor de En las tiendas griegas, empieza su Histoire con una minúscula en medio de una frase). Esta estrategia es signo de la voluntad del Nouveau roman de atenuar la jerarquía del acto inaugural ${ }^{6}$. La suspensión del eje temporal por la repetición, la multiplicación de los deícticos y el uso de verboides en lugar de verbos conjugados son -según Del Lungomodos de manifestar la convicción de que la palabra trata en vano de reorganizar un mundo incomprensible y fugitivo, un punto de vista que Saer comparte con el Nouveau roman, más allá de sus distancias con otros principios de esa estética?

El análisis genético del corpus saeriano confirma que este tipo de comienzos es el resultado de un trabajo absolutamente consciente. En el caso de "Balnearios", por ejemplo, el incipit in media verba no nace con la primera versión, sino posteriormente. La primera versión de ese texto publicado en 1976 (escrita en una agenda del año 68) empezaba:

\section{LOS BALNEARIOS}

Yo vi el mar una tarde de marzo, envuelto por el viento que crujía y que rompía contra unas las piedras ásperas olas etyas gotas que se pulverizaban hasta formar contra el sol débil un abanico de un talco irisado y más grávido. Pero en el río las orillas destellan, lentas, como señales, cabrillean, apretando el agua alrededor de color caramelo que no viene a morir a nuestros pies como el mar el agua del mar, sino que pasa. El mar es...

La primera frase desaparece de la segunda versión (escrita en un papel suelto durante un viaje a Roma) y también de la versión a máquina (que transcribe y fija esa segunda versión). Ambas, fechadas en 1969, optan un incipit in media verba, que es el que Saer elige luego en la versión definitiva:

\section{BALNEARIOS}

Pero en el río las orillas destellan, lentas, como señales, cabrillean. El mar es único y el mismo, siempre. No se mueven más que sus límites, y en el lugar, y cuando avanza una orilla, es todo el mar que avanza y

\footnotetext{
${ }^{6}$ Cf. Andrea Del Lungo, "In media verba", en op. cit., pp. 122-126.

${ }^{7}$ Cf. Sobre la relación de Saer con el nouveau roman, véanse sus "Notas sobre el Nouveau Roman”, 1972 (en El concepto de ficción, Buenos Aires, Ariel, 1997).
} 
se corre para comer un alimento de roca. Nos paramos frente al mar,

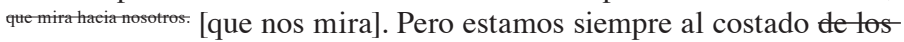
ríos del río que pasa sin tocarnos, desdeñosamente. Los balnearios son una caravana inmóvil de todos, colorados, azules, naranja anaranjados, con rayas blancas, verdes, con lunares. La arena amarilla se despliega frente al agua caramelo en un semicírculo débil. Pasan cuerpos socarrados corriendo sobre el borde del agua, y en la orilla se forma una la triple franja de un arcoiris insólito : el borde amarillos de la arena, el agua leonada, y la franja transparente, entre las dos, del agua sacudida por el repiqueteo de los pies que convulsionan la orilla. Siguiendo ho= rizontalmente con la mirada los pies que corren, sin tener en cuenta las sacudidas anteriores que ya se han borrado, manteniéndose siempre con la vista clavada en los pies que golpean e agua, uno se puede percibir la franja blancuzca, transparente, como una línea imaginaria de puntos, entre la arena y el río. Si esta descripción pudiese parecer rebuscada, basta con recordar que franjas, por decirlo así, más estables, como las franjas blancas y rojas de los toldos, son también, si se quiere, en el fondo, franjas imaginarias y discontinuas. ${ }^{8}$

Si volvemos ahora hacia atrás en la obra de Saer, constatamos que, de manera análoga a lo que ocurría en "Balnearios", en el caso de $E l$ limonero real (que fue publicado en 1974) la primera versión de un posible comienzo (fechada en enero de 1964 y titulada "Los limones bajo la luna") era una descripción del limonero:

El limonero real, cuyas ramas entrelazadas sostienen el peso de las hojas, llenas de manchas blancas de la luz de la luna ; pleno en toda estación, está cargado de azahares, parecidos también a manchas lunares, y botones blancos a punto de reventar..."

\footnotetext{
${ }^{8}$ En la versión definitiva de "Balnearios" leemos: "Pero en el río las orillas destellan, lentas, como señales: cabrillean. El mar es único y el mismo, siempre. No se mueven más que sus límites, y en el lugar, y cuando avanza una orilla, es todo el mar el que avanza. Nos paramos frente al mar, que nos contempla. Pero estamos siempre al costado del río que pasa sin mirarnos, desdeñosamente. Losbalnearios son una caravana inmóvil de toldos colorados, azules, anaranjados, con rayas blancas, verdes, con lunares. La arena amarilla se despliega frente al agua caramelo en un semicírculo débil. Pasan cuerpos quemados corriendo sobre el borde del agua, y en la orilla se forma la franja triple de un arco iris insólito: el borde amarillo de la arena, el agua leonada, y la franja transparente, entre las dos, del agua sacudida por el repiqueteo de los pies que convulsionan la orilla. Siguiendo con la mirada los pies que corren, sin tener en cuenta las sacudidas anteriores que ya se han borrado, manteniendo siempre la vista clavada en los pies que golpean el agua, se puede percibir la franja blancuzca, transparente, como una línea imaginaria de puntos, entre la arena y el río. Si esta descripción parece rebuscada, basta con recordar que franjas, por decirlo así, más estables, como las franjas blancas y coloradas de los toldos son también si se quiere, en el fondo, franjas imaginarias y discontinuas." (en $L a$ mayor, "Argumentos", 1976).
} 
En cambio en el segundo intento (escrito ese mismo año 1964) el inicio era: "Sabe amanecer, y ya estoy con los ojos abiertos", palabras en las que se empieza a vislumbrar la versión definitiva, aun cuando el uso de un verbo con sentido iterativo ("saber" utilizado en el sentido de "soler") y la opción por un narrador homodiegético relativizaran todavía la violencia de la entrada en la escritura. La tercera versión manuscrita, del mismo año, mucho más cercana a la definitiva, reformula el comienzo en tercera persona sin ninguna aclaración previa ("Amanece / y ya está con los ojos abiertos"). El empleo del presente sin verbo iterativo sitúa claramente al lector ante un discurso ya comenzado (in medias res, in media verba).

En el caso de Lo imborrable, novela publicada en 1992, hay una primera versión -titulada Lo intermedio- escrita en las primeras páginas de una agenda de 1988 y que está fechada el 26/6/88. Esta primera versión comienza con una reflexión que se plantea como anterior al comienzo, pero que a pesar de ello es relativamente clara:

\section{LO INTERMEDIO}

\section{$28 / 6 / 88$}

Lo vengo pensando: tal vez antes de empezar, sea necesario explicar dónde me encuentro en este momento, dónde estoy parado, como se dice, a qué altura de mi vida y en qué situación.

Las tres versiones siguientes (dos de ellas sin fecha, redactadas una a continuación de la otra en un papel suelto y otra en la misma agenda, en la página siguiente a la primera versión, pero con fecha del 29/11/88) optan, en cambio, una vez más, por un incipit in media verba:

Segunda versión:

Han pasado, como venía diciendo hace un momento, veinte años: anochece. Y todo esto es continuo - continuo. No para, viene diciéndose, desde hace unos segundos, mientras termina de arreglarse fente al espejo, calzándose el sobretodo negro por encima de un pullóver blanco de cuello alto y de un pantalón de franela.

\section{Tercera versión:}

Han pasado, como venía diciendo hace un momento, veinte años: anochece. Y todo esto es, sin lugar a dudas, continuo - continuo; no para. Noche y día, segun día tras día, segundo a segundo, desde que, en el vientre de ella, la gota de semen, las combinaciones inconcebibles, empezaron a multiplicarse y a volverse cada vez más complicados, la 
cosa no para, es continuo, continua, viene diciéndose, bajo los tubos de neón de todos colores que flotan en la primera oscuridad de la calle...

Cuarta versión:

CAMPOS DE PLUMA

$\begin{array}{ll}\text { CONTINUO } & \text { LO IMBORRABLE } \\ \text { 29/11/88 } & \text { NEON Y REMINISCENCIAS : UN CAFE } \\ \text { (Han pasado) } & \end{array}$

Pasaron, como venía diciendo hace un momento, veinte años: anochece. Con sorpresa, casi conmal hummor indignación, con tm atisbos de pánico, a decir verdad, [en las pupilas], Tomatis echado ligeramente artás la cabeza observa al empresario calvo y de bigotes, einetrentón (bajo) que, saliendo del bar Modelo, ha cruzado rápido la calle al verlo venir y plantándose en medio de la verda y pronunciano su nombre, ${ }^{10}$ intercepta (su paso) con una sonrisa zalamera ${ }^{\text {(melosa) }}$.

Huelga decir que la palabra "Continuo" (o "Continúo") antes del título en esta cuarta (y última) versión manuscrita del incipit de Lo imborrable subraya el comienzo in media verba o in media scripta.

\section{II) Circularidades}

Además de los comienzos en medio de una acción o en medio de un discurso, otra manera frecuente de insistir en la continuidad es el trabajo con la circularidad, trabajo que a veces se realiza a través de un juego de engarce o de ecos entre el incipit y el excipit y que en otros casos surge de la recurrencia del incipit como leit-motiv a lo largo de toda una novela.

Los ejemplos más evidentes de la primera modalidad (juego entre el incipit y el excipit) son El limonero real (1974) -que se abre y se cierra con el mismo enunciado ("Amanece / y ya está con los ojos abiertos")-, Nadie, nada, nunca (1980) - que comienza con "No hay, al principio, nada" y se cierra con "la nada universal" -, El entenado (1983) -cuyo incipit presenta al narrador en medio de la tribu, durmiendo "a la intemperie, casi aplastados por las estrellas" y cuyo excipit vuelve sobre ese mismo narrador, sentado "en una pieza blanca, a la luz de las velas ya casi consumidas, balbuceando sobre un encuentro casual entre, y con, también, a ciencia cierta, las estrellas". A esta serie podría agregarse La ocasión (1988), cuyo excipit ("Hic incipit pestis") utiliza la palabra latina "incipit", sugiriendo de algún modo un retorno al punto de partida. 
La segunda forma en que se manifesta la circularidad en Saer es a través del incipit leit-motiv, muy evidente en dos de los ejemplos ya citados: El limonero real (1974) y Nadie, nada, nunca (1980). En estas novelas las frases de ataque ("Amanece, y ya está con los ojos abiertos" en el primer caso y "No hay, al principio, nada" en el segundo) no sólo se repiten al principio y al final sino que reaparecen textualmente muchas otras veces ${ }^{9}$. En otros casos la repetición no es textual, sino que toma la forma del resumen: es el juego que se da entre el comienzo del capítulo ${ }^{10}$ y el comienzo del capítulo 2 de Glosa (1985) y también entre los comienzos del capítulo 1 y 3 de La pesquisa (1994) ${ }^{11}$.

El estudio de los manuscritos de Saer confirma la importancia que tienen para él los comienzos. Saer avanzaba en la redacción de sus novelas haciendo modificaciones puntuales, correcciones de estilo, pero la estructura, e incluso los párrafos, nacían de una vez y para siempre. De cada una de las páginas de sus novelas (excepto de Cicatrices, que fue escrita directamente a máquina) hay sólo una versión, escrita a mano. Saer elaboraba su versión definitiva cuando pasaba a máquina

\footnotetext{
${ }^{9}$ En El limonero real el incipit vuelve textualmente nueve veces más a lo largo de toda la novela. En Nadie, nada, nunca el incipit vuelve textualmente cinco veces más, al comienzo de los capítulos I, II, VIII, X, XII, XV.

${ }^{10}$ Hasta aquí todo está escrito en azul y luego todo sigue en negro, pero el título y el párrafo que describe las cuatro franjas están tachados en negro, lo que permite suponer que fueron tachados en el momento de la redacción de los párrafos siguientes.

${ }^{11}$ Glosa, cap. 1: "Es, si se quiere, octubre, octubre o noviembre, del sesenta o del sesenta y uno, octubre tal vez, el catorce o el dieciséis, o el veintidós o el veintitrés tal vez, el veintitrés de octubre de mil novecientos sesenta y uno pongamos - qué más da."
}

Glosa, cap. 2: "Estábamos en que Leto y el Matemático, una mañana, la del veintitrés de octubre de mil novecientos sesenta y uno habíamos dicho, un poco después de las diez, se habían encontrado en la calle principal, habían empezado a caminar juntos en dirección al Sur y el Matemático, a quien a su vez se lo había contado Botón en el puente superior de la balsa a Paraná, el sábado anterior, se había puesto a contarle a Leto la fiesta de cumpleaños de Jorge Washington Noriega, a finales de agosto, en la quinta de Basso en Colastiné."

La pesquisa, cap. 1 "Allá, en cambio, en diciembre, la noche llega rápido. Morvan lo sabía. Y a causa de su temperamento y quizás también de su oficio, casi inmediatamente después de haber vuelto del almuerzo, desde el tercer piso del despacho especial en el bulevar Voltaire, escrutaba con inquietud las primeras señales de la noche a través de los vidrios helados de la ventana y de las ramas de los plátanos..."

La pesquisa, cap. 3: "Morvan estaba, como les decía, mirando por la ventana la caída de la noche que allá, en diciembre, alrededor de Navidad, llega rápido, cuando, después de golpear con firmeza a la puerta y sin darle tiempo a responder, sus tres principales colaboradores, el comisario Lautret y los inspectores Combes y Juin entraron en la oficina." 
esa primera -y única- versión manuscrita ${ }^{12}$. Sólo hay verdaderos borradores (y muchas veces más de uno) en los comienzos de sus novelas. Sus incipits (y en menor medida sus excipits) son la excepción que confirma la regla, porque son las únicas zonas de las novelas a las que el escritor llega después de pasar por varios ensayos.

\section{III) Intertextualidad}

Una tercera forma de insistencia en la continuidad es el trabajo intertextual. Es cierto que la intertextualidad es importante en el conjunto del corpus saeriano y no exclusivamente en los incipits y excipits, pero no parece casual que sea en los bordes de cada texto donde los juegos con otros textos aparecen de manera casi sistemática. Si los incipit in media verba insisten en la continuidad de la obra saeriana y las repeticiones de la frase de ataque subrayan la continuidad en el seno de un mismo texto, la intertextualidad pone en evidencia la continuidad del corpus saeriano con textos claves de la literatura occidental: el incipit de la obra maestra de Proust resuena en el de "La mayor", el del Génesis en el incipit de Nadie nada, nunca, el género picaresco en el incipit de El entenado ${ }^{13}$ y el comienzo de "Tema del traidor y del héroe" de Borges en las primeras líneas de Glosa. El juego intertextual suele comenzar, por otra parte, antes del incipit, ya que muchas novelas de Saer presentan uno o varios epígrafes.

El estudio de los excipits también demuestra el peso de los intertextos: en la palabra "estrellas" al final de El entenado resuena La divina comedia de Dante ${ }^{14}$. Los dos excipits de novelas de Saer escritos en

\footnotetext{
${ }^{12}$ Para un estudio completo de dos manuscritos, $c f$. "Un arte de escribir. Los manuscritos de Glosa y El entenado" de Julio Premat, Diego Vecchio y Graciela Villanueva, Colección Archivos. Se trata, en efecto, sobre todo en el caso de Glosa, de versiones desechadas del incipit y ese artículo reflexiona sobre los motivos por los cuales no le resultaron satisfactorias a Saer como principios de su novela.

${ }^{13}$ Sobre el intertexto proustiano en los bordes de Glosa, Julio Premat, Diego Vecchio y Graciela Villanueva, "Un arte de escribir. Los manuscritos de Glosa y El entenado", en Juan José Saer, Glosa. El entenado, op. cit. 2010, pp. 473-579

${ }^{14}$ El excipit de El entenado, novela escrita también nel mezzo del camin de la vida de un escritor, termina, como cada una de las partes de La Divina Comedia de Dante, con la palabra "estrellas" ("E quindi uscimmo a riveder le stelle." Inferno, "puro e disposto a salire alle stelle.", Purgatorio, "l'amor che move il sole e l'altre stelle.", Paradiso). Sobre este juego intertextual, cf. la reflexión de Italo Calvino sobre el comienzo y el fin de la ficción ("Commencer et finir" de 1985, traducción de Jean-Paul Manganaro en Défis aux labyrinthes, éd. du Seuil, 2005, vol. II, p. 105-121).
} 
latín -el de Cicatrices (que remite a San Pablo) y el de La ocasión (que repite la frase hecha con la que los documentos oficiales antiguos registraban el comienzo de una peste)- constituyen finales que no cierran, ya que obligan al lector a una decodificación erudita que hace que el texto de algún modo se prolongue más allá de la última palabra de la última página.

\section{IV) Los incipits desechados. Estudio de un caso: Nadie, nada, nunca}

Hemos mostrado los mecanismos que subrayan la continuidad, la fluidez, en la obra de Saer. El estudio de sus manuscritos nos permite además analizar lo que no sobrevive en la versión definitiva, por ejemplo lo que Saer llamaba sus "falsas partidas", que son esos intentos de empezar que no prosperan. El estudio de los borradores permite identificar a veces el núcleo del que partió la escritura y descubrir en algunos casos cómo ciertos elementos descartados para el inicio de una ficción fueron reulilizados posteriormente. Un caso particularmente interesante es el del manuscrito de Nadie, nada, nunca, novela publicada en 1980, pero que Saer comenzó a escribir en 1971.

Veamos la primera versión del incipit de esta novela :

Músiea de aeordeón, tejana melaneóliea, aproximnándose.

Entra del Canter, aeompañado del minsieo

ElCantor

Presten todos ateneión

queenesta breve reseña

ROSA Y DORADA LA RIBERA, LA RIBERA ROSA Y DORADA $(19 / 11 / 71)$

\section{EL MEDIODÝA}

S⿺bre las cuatro franjas, roja, amarilla, verde, violeta, el cuerpo deła mujer, oxguido, mirando hacia la ventana, en la luz ardua, sin matices, plena, se destaca resalta. La cabeza, contra la franja roja del cielo, el pecho y los hombros, contra la franja amarilla de Ta isla, del otro lado del agua, el vientre desnuct entre el corpino y el calzón de la bikini , blanca, contra el río verde, las preseas calcáreas contra la playa violeta. En el fondo, por así decir, se ten copas dearomos, del color, a esa hora, de la tierra, o sea blanea. Y el sol, el sol, invisidele, continuo, del que lo protegen, ¿hasta cuándo ?, las persianas, presente, también, es sabido, en lo invisibłe, el sol, puede percibirlo, sube, los últimos tramos, fascinando entero el mes irreal, febrero.

Pasó un día entero. 
Estaba estirando, distraído, hacie el pedazo de pan, la mano, cuando vio venir, desde la pared blanca, sobre las baldosas rojas, rápida, la araña. Se levantó. La mano, volviendo rápida instintivamente hacia el cuerpo, rozó el vaso de vino a medio łenar vaciar y lo volcó : el vino derramado empapó el pedazo de pan, mojó la madera lisa, blanca de la mesa, se extendió hacia el borde y comenzó a gotear sobre las baldosas. El Gato eaminó fue al encuentro de la araña que, al presentir, desvió cambió de golpe su dirección y empezó a correr en direeción hacia el fogón. La suela de la alpargata la alcanzó ; la araña desapareció un momento bajo la suela ; y en seguida, al retirar el pie, el Gato vio el puñado de arañitas que corrían despavoridas, en estampida, en todas direcciónes y el cuerpo de su padre madre, no completamente deshecho, pataleando débilmente sobre una manchita húmeda, negruzca, contra el fondo liso de la baldosa roja. ¥ no debería, no debería pasar solo semanas enteras en esa easa.

[Hegible taehado] Y yo, mi amigo Garay, yo, como Heráclito de Efeso y el general Mitre en el Paraguay, no viá dejar más que fragmentos, le decía, recibiendo el mate Heno de vacío de sus manos, esa misma tarde, bajo la parra, Washington Noriega..$^{15}$

Al considerar este incipit, la primera observación (la más evidente) es que en 1971 la novela no tenía aún título. La segunda observación, que tiene que ver con la totalidad de esta primera página, es que ninguno de los elementos de este primer incipit pervivió textualmente en la versión definitiva del comienzo de la novela.

Los elementos fundamentales de esta primera versión del comienzo de la novela son:

1) la referencia a un cantor popular,

2) la cita de un poema de Juan L. Ortiz ("Rosa y dorada la ribera...”),

3) la referencia al mediodía y la descripción del cuerpo de una mujer que se recorta contra las cuatro franjas de color del paisaje que puede verse a través de una ventana,

4) la escena en que el Gato mata a la araña,

5) un fragmento de conversación de Washington Noriega con el Gato.

\footnotetext{
${ }^{15}$ Todo lo escrito en negro está tachado en negro.
} 


\section{Juan L. Ortiz}

La única línea que no está tachada en el manuscrito es la cita del poema de Juan L. Ortiz. He aquí el poema completo:

Rosa y dorada...

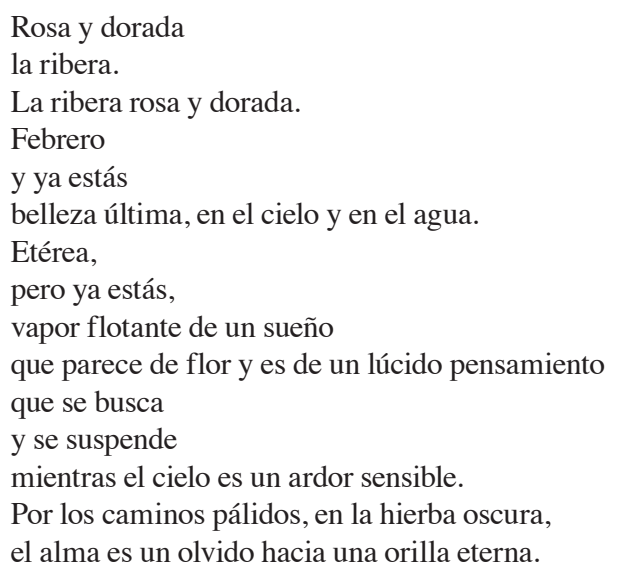

Juan L. Ortiz

La cita del poema se mantiene en la segunda versión del incipit (escrita en 1972, en la que ya aparece el título de la novela), pero luego desaparece de la versión definitiva del comienzo. Sin embargo la atmósfera que este poema crea está presente en toda la novela, como también muchos otros elementos tachados del primer incipit. Del poema de Ortiz subsistirán, en el incipit definitivo, el río, el color dorado (que ya no se atribuye a la ribera sino al río), la isla, la sensualidad y la poesía de la descripción, el sol y la observación del paisaje a través de una ventana (en la versión definitiva el Gato es el que mira). En el conjunto de la novela perviven además la ribera, el mes de febrero, el pensamiento suspendido y su correlato, la percepción fragmentaria (la del bañero, la del narrador).

A decir verdad, de los cinco elementos que hemos distinguido en la "falsa partida" de Nadie, nada, nunca, el único que desaparece por completo es la referencia al cantor y el tono popular de las primeras líneas tachadas. La escena en que el Gato mata a la araña reaparece, pero no en el incipit sino en la segunda página de la versión definitiva de la novela. Y la imagen de las cuatro franjas de color del paisaje, en cambio, aparece reescrita en otro capítulo de la novela. En cuanto al fragmento de conversación entre Washington y el Gato que cierra el 
primer ensayo de incipit (sobre los fragmentos de Heráclito y del general Mitre), aunque desaparece de Nadie, nada, nunca, lo reencontramos muchos años más tarde en otra novela de Saer.

\section{La araña: un intertexto de Robbe-Grillet}

Aunque en la versión definitiva ocupe un lugar diferente, es indudable que la escena de la araña forma parte del núcleo genético de Nadie, nada, nunca (consignado por escrito en 1971). Esta escena aparece después del relato de la llegada del Ladeado, que es la secuencia en torno a la cual se organiza el incipit definitivo. La segunda versión de la escena de la araña (escrita en 1972) perfecciona la primera, pero manteniento los elementos fundamentales de la versión anterior:

... Contra la pared está el cenicero, de barro cocido, y entre su cuerpo y la pared, en desorden, las alpargatas. Y sobre el cenicero, negra, inmóvil, adherida al barro ahumado, súbita, la araña.

Aunque la punta de la alpargata casi la toca, sigue inmóvil, como si fuese un dibujo negro, una mancha Rorschach estampada en la cara exterior del cenicero. Pero es demasiado gorda para dar esa ilusión. Y emite, porque está viva, algo, un fluido, una corriente, que permite, incluso sin haberla visto, saber que está ahí. Cuando la alpargata la toca retrocede un momento -parece como que va a retroceder pero no hace más que poner en movimiento las patas traseras-y después salta hacia un costado, despegándose del cenicero. No ha terminado de tocar el suelo que ya la planta de la alpargata, que el Gato blande, la aplasta contra la baldosa colorada. El centro del cuerpo negro se ha convertido en una masa viscosa, pero las patas continúan moviéndose, rápidas. El Gato, la alpargata en alto dispuesto a dejarla caer por segunda vez, permanece inmóvil: de la masa viscosa ha comenzado a salir, después de un momento de confusión, un puñado de arañitas idénticas, réplicas reducidas de la que agoniza, que se dispersan, despavoridas, por la habitación. En la cara del Gato se abre camino una sonrisa perpleja, maravillada, y después de un segundo de vacilación, la alpargata vuelve a golpear contra la baldosa, resonando. Ahora la mancha ha quedado inmóvil y definitiva, adherida a la baldosa colorada. El Gato mira a su alrededor: de las recién nacidas, producto de la rápida multiplicación que acaba de operarse, ni rastro.

Esta escena tiene un antecedente ilustre: el episodio en que el supuesto amante de la esposa del narrador mata a un ciempiés (al que se presenta la como un "ciempiés-araña") es una escena paradigmática de una novela paradigmática del Nouveau Roman: La jalousie de Alain 
Robbe-Grillet, publicada en $1957^{16}$. En esa novela francesa se narra una y otra vez el episodio y una y otra vez contempla el narrador, a través de la celosía, la imagen de la mancha del ciempiés muerto sobre la pared. Esa imagen obsesiva se percibe como el correlato de los celos, de la impotencia, de la violencia contenida del narrador y se asocia también a la escritura, puesto que para tratar de hacerla desaparecer es preciso utilizar una goma de borrar. He aquí, a modo de ejemplo, una de las escenas de La jalousie tramadas en torno al ciempiés:

Sur le mur d'en face, le mille-pattes est là, à son emplacement marqué, au beau milieu du panneau.

Il s'est arrêté, petit trait oblique long de dix centimètres, juste à la hauteur du regard, à mi-chemin entre l'arête de la plinthe (au seuil du couloir) et le coin du plafond. La bête est immobile. Seules ses antennes se couchent l'une après l'autre et se relèvent, dans un mouvement alterné, lent mais continu.

A son extrémité postérieure, le développement considérable des pattes -de la dernière paire, surtout, qui dépasse en longueur les antennes-fait reconnaître sans ambiguïté la scutigère, dite «mille-pattes », ou encore « mille-pattes-minute » à cause d'une croyance indigène concernant la rapidité d'action de sa piqûre, prétendue mortelle. Cette espèce est en réalité peu venimeuse ; elle l'est beaucoup moins, en tout cas, que de nombreuses scolopendres fréquentes dans la région.

Soudain la partie antérieure du corps se met en marche, exécutant une rotation sur place, qui incurve le trait sombre vers le bas du mur. Et aussitôt, sans avoir le temps d'aller plus loin, la bestiole choit sur le carrelage, se tordant encore à demi et crispant par degrés ses longues pattes, tandis que les mâchoires s'ouvrent et se ferment à toute vitesse autour de la bouche, à vide, dans un tremblement réflexe.

Dix secondes plus tard, tout cela n'est plus qu'une bouillie rousse, où se mêlent des débris d'articles, méconnaissables.

Mais sur le mur nu, au contraire, l'image de la scutigère écrasée se distingue parfaitement, inachevée mais sans bavure, reproduite avec la fidélité d'une planche anato- mique où ne seraient figurés qu'une partie des éléments : une antenne, deux mandibules recourbées, la tête et le premier anneau, la moitié du second, quelques pattes de grande taille, etc.

${ }^{16} \mathrm{Cf}$. Myrna Solotorevsky, "Connotadores de escrituralidad en textos de Reinaldo Arenas, Juan José Saer y Juan (Carlos) Martini”, en Encuentros y desencuentros de culturas: siglos XIX y XX, Actas Irvine, 1992, p. 267, consultado en junio de 2010 en: http://cvc. cervantes.es/literatura/aih/pdf/11/aih_11_4_032.pdf 
Le dessin semble indélébile. Il ne conserve aucun relief, aucune épaisseur de souillure séchée qui se détacherait sous l'ongle. Il se présente plutôt comme une encre brune imprégnant la couche superficielle de l'enduit.

Un lavage du mur, d'autre part, n'est guère praticable. Cette peinture mate ne le supporterait sans doute pas, car elle est beaucoup plus fragile que la peinture vernie ordinaire, à l'huile de lin, qui existait auparavant dans la pièce. La meilleure solution consiste donc à employer la gomme, une gomme très dure à grain fin qui userait peu à peu la surface salie, la gomme pour machine à écrire, par exemple, qui se trouve dans le tiroir supérieur gauche du bureau. ${ }^{17}$

Además del diálogo con el Nouveau roman, si tenemos en cuenta el enorme peso que tiene lo pulsional en Nadie, nada, nunca (sobre todo en sus variantes más violentas) no resulta sorprende que la escena de la araña haya formado parte del núcleo genético del proyecto. Dicho de otro modo, no sorprende que Saer incluya una araña en el comienzo de una historia que girará en torno a un Gato y varios c/Caballos. En la versión de Saer, por otra parte, aunque la escena no se repite, la muerte de la araña está subrayada por su posición inicial y por su carácter ambiguo, ya que se trata a la vez de una escena de muerte y de nacimiento.

\section{Héráclito y el general Mitre}

El enunciado que cierra la primera "falsa partida" de Nadie, nada, nunca es una reflexión sobre la imposibilidad de constituir un todo coherente (en la vida, en el arte, en la percepción, en la construcción del sujeto). La frase no se reutiliza en la misma novela, pero reaparece textualmente en Glosa casi quince años más tarde:

Manuscrito de primer incipit de Nadie, nada, nunca:

Y yo, mi amigo Garay, yo, como Heráclito de Efeso y el general Mitre en el Paraguay, no viá dejar más que fragmentos, le decía, recibiendo el mate Heno de vacío de sus manos, esa misma tarde, bajo la parra, Washington Noriega.

\section{En primer capítulo de Glosa:}

...Una sonrisa rápida, discreta y distraída, aparece y se borra en los ojos del Matemático. Pero, por alguna razón oscura, de la que ni él mismo es consciente, en vez de contar esa anécdota de Washington cuenta otra,

${ }^{17}$ Alain Robbe-Grillet, La Jalousie [1re éd. 1957], Paris, Éditions de Minuit, 2008, p. 127-129. 
en la que no ha pensado desde hace mucho tiempo y que, una fracción de segundo antes de que haya comenzado a decirla en voz alta, estaba ausente de sus representaciones.

-Dice que una vez un autor de cuentos fantásticos que lo vino a visitar de Buenos Aires le preguntó si nunca pensaba escribir una novela. Dice que Washington puso cara de espanto, como si el otro lo estuviese amenazando. $Y$ dice que después de un momento le contestó: yo, como Heráclito de Efeso y el general Mitre en el Paraguay, no viá dejar más que fragmentos.

(el subrayado es nuestro)

El enunciado sigue asociado al personaje de Washington Noriega. Nótese, por otra parte, que la referencia a Heráclito pervive en uno de los epígrafes en la versión definitiva de Nadie, nada, nunca y que la insistencia en la percepción fragmentaria subsiste como un elemento fundamental en la novela.

\section{Franjas}

Ya hemos visto que en "Balnearios" se presentaba una descripción del paisaje de la playa en términos de "franjas" de color. Al hacer esa descripción el narrador mostraba tener absoluta conciencia de que su manera de presentar el paisaje podía sorprender. Lo que le interesaba sobre todo de esa visión "en franjas" era el carácter fragmentario de la percepción.

... Pasan cuerpos quemados corriendo sobre el borde del agua, y en la orilla se forma la franja triple de un arco iris insólito: el borde amarillo de la arena, el agua leonada, y la franja transparente, entre las dos, del agua sacudida por el repiqueteo de los pies que convulsionan la orilla. Siguiendo con la mirada los pies que corren, sin tener en cuenta las sacudidas anteriores que ya se han borrado, manteniendo siempre la vista clavada en los pies que golpean el agua, se puede percibir la franja blancuzca, transparente, como una línea imaginaria de puntos, entre la arena y el río. Si esta descripción parece rebuscada, basta con recordar que franjas, por decirlo así, más estables, como las franjas blancas y coloradas de los toldos son también si se quiere, en el fondo, franjas imaginarias y discontinuas.

En la primera "falsa partida" de Nadie, nada, nunca también hay franjas, cuatro, asociadas a una mujer que mira hacia una ventana en la luz intensa de un mediodía de febrero. La descripción presenta "la cabeza, contra la franja roja del cielo, el pecho y los hombros, contra la 
franja amarilla de la isla, del otro lado del agua, el vientre desnudo [...] contra el río verde, las piernas calcáreas contra la playa violeta". Cielo rojo, isla amarilla, río verde, playa violeta, todo en la luz del mediodía. La descripción, es cierto, desaparecerá del incipit definitivo de la novela, pero en una escena en el capítulo $X$ puede percibirse una reescritura de la escena. En un momento en que Elisa, al caer la noche, se pone a mirar el balneario por la ventana, leemos:

[Elisa] se dirige hacia la habitación del frente y, abriendo la ventana de par en par y acodándose en el marco, se pone a contemplar la playa. Muchos bañistas ya se han retirado. [...] Los que quedan, seis o siete incluido el bañero que será sin duda el último en retirarse, evolucionan lentos por la playa, ennegrecidos, y sus siluetas, paradójicas, se recortan más nítidas en la luz descompuesta. El crepúsculo ha transformado el espacio visible en cuatro franjas sin profundidad, de colores diferentes: arriba, la franja ancha, verdosa, del cielo, contra la que se recorta la filigrana negra de la vegetación de la isla, entre cuyas perforaciones intrincadas reaparecen las manchas verdes del cielo; la franja violeta del agua, que viene después de la de la vegetación y que esta llena de manchitas de brillo liso que conservan su tonalidad violácea, y por último la arena azul, que anuncia la noche, y sobre la que se asientan, como incorpóreas, las siluetas movedizas de los últimos bañistas cuyos perfiles relumbran en la luz ausente y cintilante. Cuando Elisa se retira de la ventana, entornándola, el azul de la playa ya está ganando el espacio entero. En el fondo de la casa, los eucaliptos negros se recortan contra una mancha de un rojo amarillento.

Ya no es el cuerpo de la mujer el que se mira, como ocurría en la primera versión manuscrita del incipit, sino la mujer (Elisa) la que mira los cuerpos de los bañistas a través de una ventana. Y la hora elegida ya no es el mediodía sino el momento en el que se esconde el sol. Las franjas son las mismas (cielo, isla, agua y playa), pero los colores son aun más sorprendentes que en la primera versión: no hay un cielo rojo, una isla amarilla, un río verde y una playa violeta, sino un cielo verde, una isla negra, un agua violeta y una playa azul, asociaciones que muestran la voluntad de insistir en la indefinición propia del crepúsculo y en la subjetividad de la percepción.

\section{A modo de conclusión}

En un trabajo de 1971 que fue pionero en materia de reflexión sobre los incipits literarios, Claude Duchet analizaba el comienzo de Madame Bovary y escribía: “...el inicio de un texto tampoco es su comienzo: 
un texto no comienza nunca, está siempre ya comenzado". Duchet observaba que esto se verifica aun en el caso del enunciado más tradicionalmente característico del comienzo de una secuencia narrativa, como es "La marquesa salió a las cinco" (enunciado del que -dice Breton- se burlaba Paul Valéry, prometiendo que él nunca escribiría algo $\tan \operatorname{trivial}^{18}$ ) y afirmaba que incluso un enunciado como ése no puede enunciarse sino como correlato de un marco previo, que es el marco "de los códigos que rigen los horarios de las marquesas y el intertexto de los incipits". Una novela no puede, en efecto, evitar señalar que está comenzando. El texto que la precede -afirma Duchet- es también lo que está fuera del texto, la prosa del mundo que se cuela en él desde el incipit mismo ${ }^{19}$.

Saer fue plenamente consciente de esta continuidad entre el texto y el mundo y entre cada nuevo texto y los que lo preceden en la propia obra o en la literatura en general y eligió subrayar la continuidad de múltiples maneras. El acercamiento genético confirma que existe un cuidadoso trabajo de elaboración en los bordes de las ficciones saerianas. El estudio de los incipits y excipits, sea en sus versiones manuscritas, sea en sus versiones definitivas, multiplica y enriquece nuestra comprensión de los modos en los que el escritor construyó una obra en perpetuo movimiento.

\footnotetext{
${ }^{18} \mathrm{El}$ tema ha hecho correr mucha tinta y la posibilidad de comenzar por un enunciado de ese tipo ha sido reivindicada tanto por escritores (Claude Mauriac publica, por ejemplo, en 1961 una novela que lleva ese título) como por críticos, como puede apreciarse por ejemplo -para citar sólo un caso- en el artículo “À l’ombre des récits possibles" de Radu Petrescu, que presenta una bibliografía sobre el tema. $C f$.

http://iit.iit.tuiasi.ro/philippide/asociatia/asociatia_admin/upload/III_1_Petrescu.pdf (artículo consultado en junio de 2010).

19 "Pour une sociocritique ou variations sur un incipit", en Littérature $\mathrm{n}^{\circ} 1$, Paris, Larousse, 1971, p. 5. la traducción y el subrayado son nuestros.
} 


\section{Bibliografía citada}

SAER, Juan José, El concepto de ficción, Buenos Aires, Ariel, 1997. , La narración-objeto. Buenos Aires, Seix Barral, 1999. ,El río sin orillas, Buenos Aires, Seix Barral, 1991.

(1960) En la zona, Buenos Aires, Seix Barral, 2003.

(1964) Responso, Buenos Aires, Seix Barral, 1998.

(1965) Palo y hueso, Buenos Aires, Seix Barral, 2000.

(1966) La vuelta completa, Buenos Aires, Seix Barral, 2001.

(1967) Unidad de lugar, Buenos Aires, Seix Barral, 1996.

(1969) Cicatrices, Buenos Aires, Seix Barral, 2003.

(1974) El limonero real, Buenos Aires, Seix Barral, 2002.

(1976) La mayor, Buenos Aires, Seix Barral, 1992.

(1980) Nadie nada nunca, Buenos Aires, Seix Barral, 1994.

(1983) El entenado, Buenos Aires, Seix Barral, 2000.

(1985) Glosa, Buenos Aires, Seix Barral, 2000.

(1986) La ocasión, Buenos Aires, Seix Barral, 2001.

(1988) El arte de narrar, Santa Fe, UNL.

(1992) Lo imborrable, Buenos Aires, Seix Barral, 2002.

(1994) La pesquisa, Buenos Aires, Seix Barral.

(1997) Las nubes, Buenos Aires, Seix Barral, 2004.

(2000) Lugar, Buenos Aires, Seix Barral.

(2001) Cuentos Completos (1957-2000). Buenos Aires, Seix Barral.

(2005) La grande, Buenos Aires, Seix Barral.

(2010) Glosa. El entenado, Córdoba (Argentina), Alción Editora /colección Archivos de l'UNESCO.

Calvino, Italo, “Commencer et finir”, 1985, traducción de Jean-Paul Manganaro en Défis aux labyrinthes, éd. du Seuil, 2005, vol. II, p. 105-121.

Del Lungo, Andrea, L'incipit romanesque, Paris, Seuil, 2003. 
Duchet, Claude, "Pour une sociocritique ou variations sur un incipit", en: Littérature $\mathrm{n}^{\circ} 1$, Paris, Larousse, 1971.

Petrescu, Radu, “À l'ombre des récits possibles”, en: http://iit.iit.tuiasi.ro/ philippide/asociatia/asociatia_admin/upload/III_1_Petrescu.pdf

Premat, Julio, Héroes sin atributos, Buenos Aires, Fondo de Cultura Económica, 2009.

, La dicha de Saturno, Rosario, Beatriz Viterbo, 2002

Premat, Julio, Vecchio, Diego y Villanueva, Graciela "Un arte de escribir. Los manuscritos de Glosa y El entenado", en Juan José Saer, Glosa. El entenado, op. cit. 2010, pp. 473-579.

Robbe-Grillet, Alain, La Jalousie [1re éd. 1957], Paris, Éditions de Minuit, 2008.

Solotorevsky, Myrna, "Connotadores de escrituralidad en textos de Reinaldo Arenas, Juan José Saer y Juan (Carlos) Martini”, en Encuentros y desencuentros de culturas: siglos XIX y XX, Actas Irvine, 1992. 